\title{
Karakteristik Klinis Trauma Kepala pada Anak di RS Dr. Cipto Mangunkusumo Jakarta
}

\author{
Msy Rita Dewi MS, * Irawan Mangunatmadja, ${ }^{* *}$ Yeti Ramli*** \\ * Bagian Neurologi Bagian Ilmu Kesehatan Anak Fakultas Kedokteran Universitas Sriwijaya \\ ** Divisi Neurologi Bagian Ilmu Kesehatan Fakultas Kedokteran Universitas Indonesia \\ *** Divisi Neuro Pediatri Bagian Neurologi Fakultas Kedokteran Universitas Indonesia
}

\begin{abstract}
Latar belakang. Cedera kepala merupakan salah satu penyebab anak dibawa ke rumah sakit. Pada umumnya trauma terjadi karena kecelakaan lalu lintas. Di Amerika sekitar 300.000-400.000 anak dirawat karena cedera. Di Indonesia hanya ada data sporadis.

Tujuan. Mendapatkan gambaran karakteristik klinis pada anak dengan cedera kepala di RS Dr. Cipto Mangunkusumo.

Metode. Studi deskriptif retrospektif dengan data sekunder diambil dari data catatan medik dari bulan Januari 2004 - Juli 2005.

Hasil. Selama kurun waktu penelitian ditemukan jumlah kasus trauma kepala pada anak usia $<15$ tahun 503 kasus. Usia terbanyak antara umur 6-10 tahun, rasio laki-laki: wanita adalah 1.7: 1. Keluhan terbanyak adalah nyeri kepala (25,6\%), dan muntah (20,9\%). Mekanisme cedera banyak yang tidak diketahui (61,6 \%). Skala koma Glasgow (SKG) 13-15 yang paling banyak dijumpai $(91,8 \%)$, gangguan saraf kranialis dan gangguan motorik (1,2\%), dan Jejas hematom 9,5\%. Pemeriksaan radiologik sederhana jarang dikerjakan. Enam puluh persen pemeriksaan rawat inap, $61 \%$ dan $36,4 \%$ hidup tanpa cacat.

Kesimpulan. Kasus trauma kepala pada anak usia $<15$ tahun, lebih sering terjadi pada anak laki-laki dibanding anak perempuan kelompok usia terbanyak antara 6-10 tahun. Fraktur tengkorak dan perdarahan intrakranial jarang terjadi pada anak-anak. (Sari Pediatri 2008; 9(5):354-8).
\end{abstract}

Kata kunci: cedera kepala, karakteristik klinis

Alamat korespondensi

Dr. Msy Rita Dewi, SpA. Bagian Ilmu Kesehatan Anak FK Unsri/RSMH Jl. Jend. Sudirman km 3,5 Palembang.

Telepon: (0711) 354088 Ext. 507, 372832, 376445, Fax.: (0711) 372832

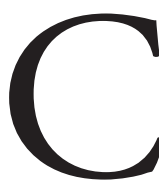

edera kepala merupakan salah satu penyebab anak di bawa ke rumah sakit. ${ }^{1,2}$ Para orang tua dari hampir 5 juta anak di Amerika yang datang ke bagian emergensi rumah sakit meminta agar dokter mengevaluasi dan merawat anaknya yang jatuh. ${ }^{3}$ Pada 
umumnya, trauma kepala terjadi karena kecelakaan lalulintas, jatuh dari sepeda, jatuh terpeleset, jatuh dari kursi, meja, atau akibat tindak kekerasan pada anak.

Bentuk jejas sering merisaukan para orang tua, sehingga sering terjadi keadaan panik dengan akibat mengganggu ketenangan petugas kesehatan dalam pertolongan kepada pasien dan perlu tindakan yang cepat untuk dapat menenangkan orang-orang di sekitar pasien.

Di Inggris, jumlah anak yang masuk ke rumah sakit karena cedera kepala meningkat 6 kali selama 20 tahun terakhir, sedangkan di Amerika sekitar 300.000-400.000 per tahun anak yang dirawat karena cedera. ${ }^{4,5}$ Pada penelitian di St Louis Children's Hospital yang dilakukan Quayle dan kawan-kawan, dari 322 anak yang dirawat $27 \%$ terjadi kerusakan intrakranial sedangkan fraktur kepala 16\% dengan gambaran klinis yang tidak jelas. Di India, dilakukan penelitian retrospektif oleh Suresh dan kawan-kawan, dari 340 anak yang diteliti terdapat 95 anak dengan skala koma Glasgow (SKG) <8, sedangkan 96 anak dengan (SKG) 9-12, 152 anak dengan (SKG) 13-15, dan ternyata 95 anak dengan epidural hematom (EDH). ${ }^{1,6}$ Data di bagian Neurologi FKUI/RSCM pada tahun 2000, jumlah kasus cedera $<15$ tahun sebanyak 92 kasus yang terdiri dari $73 \%$ cedera kepala ringan, $19,5 \%$ cedera kepala sedang, $76 \%$ cedera kepala berat. ${ }^{7}$

\section{Tujuan Penelitian}

Tujuan dari penelitian diharapkan diperoleh gambaran karakteristik klinik dan tata laksana yang dilakukan pada anak dengan cedera kepala sehingga para klinisi dapat membuat rencana perbaikan, di masa mendatang agar nantinya mampu memberikan pelayanan kesehatan yang optimal.

\section{Metode}

Penelitian merupakan studi deskriptif retrospektif. Data dikumpulkan dari catatan medik kasus cedera kepala yang datang berobat di IGD RS Cipto Mangunkusumo, poli rawat jalan divisi neurologi anak RSCM dari bulan Januari 2004 sampai Juli 2005.

\section{Hasil}

Selama rentang waktu studi, dijumpai 503 kasus cedera kepala berusia $<15$ tahun yang datang berobat dan dirawat. Terdiri dari 321 anak laki-laki $(63,08 \%)$ dan 182 anak perempuan $(36,92 \%)$ dengan jumlah terbesar pada usia 6-10 tahun $(29,6)$, tertera pada Tabel 1 .

Tabel 1. Distribusi kasus, keluhan, dan penyebab cedera kepala

\begin{tabular}{|c|c|c|c|}
\hline Variabel & Laki-laki & Perempuan & $\begin{array}{c}\text { Jumlah } \\
\text { (persentase) }\end{array}$ \\
\hline \multicolumn{4}{|l|}{ Umur (tahun) } \\
\hline$<1$ & 17 & 8 & $25(4,9)$ \\
\hline $1-2$ & 42 & 23 & $65(2,9)$ \\
\hline $3-5$ & 85 & 42 & $127(25,2)$ \\
\hline $6-10$ & 84 & 65 & $149(29,6)$ \\
\hline $11-15$ & 93 & 44 & $137(27,2)$ \\
\hline \multicolumn{4}{|l|}{ Keluhan } \\
\hline Nyeri kepala & & & $129(25,6)$ \\
\hline Muntah & & & $105(20,9)$ \\
\hline Kehilangan kesadara & & & $33(6,5)$ \\
\hline Perdarahan THT & & & $31(6,2)$ \\
\hline Kejang & & & $22(4,4)$ \\
\hline Lain-lain & & & $183(36,4)$ \\
\hline \multicolumn{4}{|l|}{ Penyebab } \\
\hline Kecelakaan lalu linta & & & $110(21,9)$ \\
\hline Jatuh dari ketinggian & & & $59(11,7)$ \\
\hline Dipukul & & & $13(2,6)$ \\
\hline Jatuh dari kereta api & & & $11(2,2)$ \\
\hline Tidak diketahui & & & $310(61,6)$ \\
\hline
\end{tabular}

Tabel 2. Keadaan neurologi dan hematom pasien cedera kepala

\begin{tabular}{lcc} 
Keadaan Neurologi & Jumlah kasus & Persentase \\
\hline Kondisi Neurologi & & \\
$\quad$ SKG* saat masuk & & \\
$\quad<8$ & 8 & 1,6 \\
$9-12$ & 33 & 6,6 \\
$\quad 13-15$ & 461 & 91,8 \\
Gangguan saraf kranial & 6 & 1,2 \\
Gangguan Motorik & 6 & 1,2 \\
$\quad$ Pupil anisokor & 9 & 1,8 \\
Hematom & & \\
Subgaleal & 33 & 6,5 \\
Kacamata/raccon & 3 & 0,6 \\
Retroaurikuler/battle & 1 & 0,2 \\
Palpebra & 11 & 2,2 \\
Tidak hematom & 455 & 90,5 \\
\hline
\end{tabular}

*SKG = Skala Koma Glassgow 
Keluhan yang terbanyak dijumpai pada kasus cedera kepala adalah nyeri kepala 129 kasus (25,6\%), muntah 105 kasus (20,9\%), dan kejang 22 kasus $(4,4 \%)$. Sebagian lainnya datang dengan keluhan muntah, kehilangan kesadaran, dan perdarahan THT. Mekanisme terjadinya cedera kepala banyak tidak diketahui oleh orang tua $(61,6 \%)$, kecelakaan lalu lintas $(21,9 \%)$, dan jatuh dari kereta api (2,2\%). Pada pemeriksaan neurologi, yang terbanyak dijumpai

Tabel 3. Radiologi dan CT-scan pada pasien cedera kepala

\begin{tabular}{lcc}
\hline & Jumlah kasus & Persentase \\
\hline Foto Kepala & & \\
$\quad$ Fraktur Linier & 47 & 25,7 \\
Fraktur Impresi & 9 & 4,9 \\
Fraktur Mandibula & 6 & 3,3 \\
Normal & 121 & 66,1 \\
Total & 183 & 100 \\
CT-scan & & \\
Edema Serebri & 15 & 7,65 \\
Intra Cerebral Hemorhagi & 12 & 6,12 \\
Epidural Hematom & 14 & 7,14 \\
Subdural Hematom & 6 & 3,06 \\
Subarachnoid Hemorhagi & 5 & 2,55 \\
Gambaran lain & 80 & 40,81 \\
Normal & 64 & 32,65 \\
\hline
\end{tabular}

Tabel 4. Terapi yang diberikan dan kondisi pasien cedera kepala setelah diterapi (outcome)

\begin{tabular}{lcc}
\hline & Jumlah kasus & Persentase \\
\hline Pengobatan & 68 & 13,5 \\
Citicholin & 34 & 6,8 \\
Piracetam & 38 & 7,6 \\
Analgetik & 7 & 1,4 \\
Manitol & 1 & 0,2 \\
Steroid & 24 & 4,8 \\
Antibiotik & 1 & 0,2 \\
Operasi & 330 & 65,6 \\
Tidak ada terapi khusus & & \\
Proporsi & & \\
Rawat inap & 183 & 36,4 \\
- Hidup tanpa cacat & 6 & 1,2 \\
- Hidup dengan cacat & 2 & 0,4 \\
- Vegetative state & 5 & 1,0 \\
Meninggal & 307 & 61,0 \\
Rawat jalan & & \\
&
\end{tabular}

dengan skala koma Glasgow (SKG) 13-15 (91,8 \%), hanya sedikit dari pasien yang mengalami gangguan saraf kranial ataupun gangguan motorik (6\%). Begitu juga untuk pemeriksaan pupil, pupil anisokor dijumpai pada 9 pasien (1,8\%) (Tabel 1).

Jejas yang tampak hanya berupa hematom, dari 503 pasien cedera kepala hanya sedikit yang mengalami hematom (9,5\%). Terbanyak terjadi di subgaleal. Pemeriksaan foto kranium, dilakukan pada 183 pasien yang dicurigai kemungkinan adanya fraktur kranium 66,1\% didapatkan hasil normal. Dari 503 pasien cedera kepala, 196 yang dilakukan pemeriksaan CTscan kepala karena alasan biaya. Pada pasien yang diperiksa CT-scan kepala, 32,65\% menunjukkan gambaran normal. Selain terdapat gambaran edema serebri atau perdarahan, pada 40,81\% kasus ditemukan gambaran lain dari CT-scan kepala seperti pneumonia, fraktur linear frontal, froccidextra (Tabel 3).

Selama perawatan, sebagian besar pasien tidak diberi terapi khusus $(65,6 \%)$. Pada pasien yang mendapat terapi khusus, jenis obat yang paling banyak dipakai adalah Citicholin (13,5\%). Dari semua pasien yang datang berobat dengan trauma kepala, sebagian besar diterapi dengan rawat jalan karena kondisinya baik (61\%). Pada pasien yang dirawat inap, sebagian besar pulang dengan kondisi hidup tanpa cacat $(36,4 \%)$ (Tabel 4).

\section{Pembahasan}

Perbandingan antara laki-laki dan perempuan (sex ratio) pada penelitian ini adalah $321: 182(1,7: 1)$ dengan kelompok usia terbanyak antara 6-10 tahun (29,6\%), rasio laki-laki dan perempuan tidak jauh berbeda dengan penelitian Reed dengan rasio laki-laki : perempuan $=1,8: 1$. hal ini diasumsikan bawa anak laki-laki lebih aktif dibandingkan anak perempuan. ${ }^{13-15}$ American Academy of Pediatric (AAP) menyatakan bahwa rata-rata usia yang sering mengalami cedera antara 2 sampai 20 tahun. Namun dari penelitian Kimberly, usia yang dijumpai terjadi cedera kepala adalah usia kurang dari 12 tahun dengan rata-rata usia 4 tahun 10 bulan. ${ }^{11,14}$

Keluhan yang terbanyak pada cedera kepala yaitu nyeri kepala $(25,6 \%)$ dan muntah $(20,9 \%)$ sedangkan kehilangan kesadaran 6,5\%. Pada penelitian Reed didapatkan bahwa keluhan yang sering adalah nyeri kepala, muntah dan letargi. Keluhan kehilangan 
kesadaran rata-rata $>5$ menit merupakan alasan utama membawa anak ke rumah sakit. ${ }^{11}$ Namun dari penelitian ini riwayat kehilangan kesadaran hanya sedikit dan juga menjadi salah satu alasan pasien dibawa ke rumah sakit.

Dari penelitian kebanyakan pasien tidak tahu bagaimana mekanisme penyebab cedera kepala (61,6\%). Kecelakaan lalu lintas merupakan mekanisme cedera yang sering dijumpai. Pada penelitian Parslow dan kawan-kawan, mekanisme cedera tergantung dari usianya. Pada usia antara 5-9 tahun mekanisme yang terbanyak adalah kecelakaan pada pejalan kaki. ${ }^{16}$

Kondisi neurologi pada saat pertama kali, SKG yang terbanyak 13-15 (91,8\%), sedang gangguan motorik, pupil anisokor dan gangguan saraf kranialis tidak banyak dijumpai. Pada penelitian Parslow SKG yang sering adalah 3-8 yang terjadi pada pejalan kaki dengan riwayat kehilangan kesadaran $>5$ menit. Pada penelitian ini SKG yang banyak dijumpai antara 13$15 \mathrm{Hal}$ ini karena pada saat anak dibawa ke rumah sakit kondisi masih baik dan mekanisme trauma mungkin tidak berat. Anak dibawa karena kepanikan orang tua melihat anaknya cedera kepala. ${ }^{16}$ Sedangkan dari penelitian Reed sebagian besar alasan anak dibawa ke rumah sakit karena ada riwayat kehilangan kesadaran. Pedoman AAP menyatakan bahwa bila terdapat riwayat kehilangan kesadaran 1 menit atau lebih merupakan indikasi untuk observasi ketat dan melakukan pemeriksaan CT-scan.

Tidak semua kasus cedera kepala dilakukan pemeriksaan radiologik sederhana. Pada penelitian ini pemeriksaan radiologik dilakukan pada 183 kasus (36,4\%). Radiologi dilakukan bila dokter mencurigai kemungkinan adanya fraktur kranium, terutama pada pasien yang tidak sanggup melakukan pemeriksaan $C T$ scan kepala. Dari kasus yang diperiksa radiologi 66,1\% normal. Hal ini tidak jauh berbeda dengan penelitian Reed bahwa dari anak dengan cedera kepala yang dilakukan pemeriksaan radiologi sederhana, terbanyak dengan hasil normal. Fraktur tengkorak biasanya jarang terjadi pada anak-anak kecuali bila ada benturan yang kuat hal ini karena adanya sifat plastis dari kepala anak. ${ }^{15}$ Namun bila dijumpai adanya fraktur tengkorak harus diwaspadai kemungkinan perdarahan intrakranial.

Pemeriksaan CT-scan hanya dilakukan pada 196 orang $(38,9 \%)$ karena kesulitan biaya. Dari pasien yang dilakukan pemeriksaan CT-scan 37 (18,9\%) orang mengalami perdarahan intrakranial. Pada anak-anak, perdarahan intrakranial biasanya disertai juga dengan fraktur di tengkorak. Dari kepustakaan pada anak di atas 5 tahun jarang terjadi perdarahan intrakranial kecuali benturan yang sangat kuat, namun pada anak $<1$ tahun sering terjadi perdarahan intrakranial (shaken baby sindrom). ${ }^{12-13}$

Terapi yang diberikan pada umumnya tidak ada yang khusus $(65,6 \%)$ namun pada kasus cedera sedang sampai berat, pasien mendapat pengobatan citikolin. Dari kepustakaan tidak ada obat khusus, namun bila terdapat perdarahan atau edema serebri maka obatobatan yang diberikan untuk mengatasi edema atau perdarahan tersebut. American Academy of Pediatric menyatakan bahwa tindakan utama adalah melakukan CT-scan bila dijumpai riwayat kehilangan kesadaran lebih dari satu menit. Untuk tindakan lanjut berdasarkan hasil temuan dari CT-scan apakah harus dioperasi atau hanya obat-obatan. ${ }^{11}$

\section{Kesimpulan}

Jumlah kasus trauma kepala pada anak usia $<15$ tahun di RSCM selama kurun waktu Januari 2004 hingga Juli 2005 sebanyak 503 pasien. Perbandingan anak laki-laki dan perempuan $1,7: 1$, dengan kelompok usia terbanyak antara 6-10 tahun. Keluhan yang terbanyak nyeri kepala dan muntah. Gangguan saraf kranialis tidak banyak dijumpai. Hasil pemeriksaan radiologi hanya sedikit yang abnormal, jarang terjadi fraktur tengkorak pada anak-anak kecuali bila ada benturan yang kuat hal ini karena adanya sifat plastis dari kepala anak. Pada pasien yang dilakukan pemeriksaan CT-Scan 7,7 \% dari seluruh kasus yang mengalami perdarahan intrakranial. Tidak ada tata laksana khusus, namun pada kasus cedera kepala sedang sampai berat, pasien diobati dengan citikholin.

\section{Daftar Pustaka}

1. Terry H. Traumatic encephalopathies. Dalam: Ronald, penyunting. Pediatric Neurology for The Clinician. Conecticut: Appleton \& Large; 1999;169-81.

2. Iskandar Japardi. Cedera kepala pada anak. Dalam: Media Bedah Saraf 2003;1:40-3.

3. Quayle KS, Jaffe DM, Kupperman N, Kauffman A. Diagnostic testing for acute head injury in children: when are head computed tomography and skull radiographs indicated? Pediatric 1997; no 5, p.e11 
4. Menkes JH, Batzdorf. Postnatal trauma an injuries by physical agents. Dalam: Menkes. Textbook of child neurology. Edisi ke-3. Philadelphia: Lippincott Williams and Wilkins;1985. h. 471-525.

5. Gerald M. Clinical paediatric neurology, a signs and symptoms approach. Philadelphia: WB Saunders Company; 1992. h. 44-50.

6. Suresh HS, Praharas SS. Prognosis in children with head injury: an analysis of 340 patients. Neurology India 2003; 51:16-8.

7. Istiana S. Prediktoer perdarahan intrakranial akibat cedera kranioserebral pada anak. Neurona 2004;21:20-5.

8. Jane M. Evaluation of head injury in paediatric emergency department. Arch Paediatric Adom.1998; 152: 1220-3.

9. Taslim. Trauma kepala. Dalam: Neurologi anak dalam praktek sehari-hari. Jakarta: Balai Penerbit FKUI;1995; 179-87.

10. Schutzmen. Evaluation and management of children younger than two years old with apparently minor head trauma: proposed guidelines Pediatrics 2001; 107:983-93.

11. American Academy of Pediatrics. The management of minor closed head injury in children (AC9858). Pediatrics 1999; 104:1407-15.

12. John DW. Pediatric head injury. Dalam: Neuroyan RK. Neurotrauma, New York: Mc Graw Hill Companies Inc;1996. h. 859-67.

13. Sherington. Clinical predictors of abnormal computed tomography scans. J of Paediatric and Child Health 2002; 38:388-92

14. Kimberly. Diagnostic testing for acute head injury in children: when are head computed tomography and skull radiographs indicated?. Pediatrics 1997; 99:11-25.

15. Reed MJ, Browning JG : Can we abolish skull $x$ rays for head injury? Arch Dis Child 2005; 90: 859-64.

16. Parslow RC, Morris KP: Epidemiology of traumatic brain injury in children recovery intensive iin the UK,.Arch Dis Child 2005; 90:1182-7. 